\title{
Enhanced Gain Microstrip Patch Antenna for Wimax Applications
}

\author{
Shaikh Reshma, Dr. B. G Hogade \\ Department of Electronics, Terna Engineering College , Nerul, Navi Mumbai, India
}

\begin{abstract}
This paper proposes a rectangular shaped microstrip patch antenna with enhanced gain which is focused to be used for wimax applications.As today there is a growing demand of wimax technology, the objective of this project is to optimize the gain of antenna and thereby study the effects of antenna dimensions Length $(L), W i d t h(W)$ and substrate parmeters, relative dielectric constant, substrate thickness on its performance.This project introduces a method using double layer with airgap to design antenna operating at $3.6 \mathrm{GHz}$ giving high performance in terms of gain and return loss.A microstrp probe feeding technique and moments based IE3D software will be used to design a microstrip patch antenna with enhanced gain.
\end{abstract}

Keywords-Air Gap, Gain, Microstrip patch antenna, dielectric constant, Return loss, VSWR.

\section{INTRODUCTION}

In today's world of wireless communication, recent developments in wireless communication industry continue to derive requirement of small, compatible and affordable microstrip patch antennas. Microstrip patch antennas are popular in wireless communication due to their various advantages such as low profile, light weight, low cost, ease of fabrication and integration [4]. Balanis [9] states that an antenna should be low profile, simple and inexpensive to fabricate and it should be easy to mount on planar and non-planar surfaces . Thus posing advantages in Wimax and antenna applications.However the applications of antenna are limited by its narrow bandwidth ,low efficiency, low gain even these antennas are compact in size.These limitations are due to feeding circuitry to some extent [4]. To cope with these shortcomings many techniques have been developed in recent years by enhancing its low gain and low bandwidth. In order to match the element the simplest matching method involves choosing the feed location where the resonant resistance is equal to feed-line impedance. In most applications, the Microstrip patch antenna is fed using either coaxial probe feed or inset Microstrip line as both are direct contact methods providing high efficiency[4] when the type of patch is to be used for an applications is choosen, the dimensions should be carefully analysed. A small change in any dimensions can cause a noticeable change in the results eg.frequency,impedance matching, bandwidth,directivity and gain etc.[1]

\section{PATCH ANTENNA DESIGN THEORY AND MODEL}

In this work instead of using an expensive low loss materials such as Teflon or ceramic,a simple rectangular patch antenna with standard low cost FR 4 laminate is utilized which also has loss tangent of 0.019 . An air gap between radiating element and ground plane is inserted to obtain a high gain and high efficiency. The air gap reduces both the electric field concentration on the lossy epoxy and the dielectric constant of the radiating plane.This antenna uses microstrip probe feed technique because this feed can be placed at any point in the patch to match with its input impedance. To demonstrate the proposed antenna, a $3.6 \mathrm{Ghz}$ MPA with air gap is designed for wimax applications and is thereby simulated, fabricated and tested. Finally the design is accomplished using a second layer of FR 4 which is coated with a upper film at both sides and a airgap between them.

The design of double layer with air gap MSA has been calculated by using following equation below.

I. $\mathrm{W}=\mathrm{c} \sqrt{\frac{(\epsilon r+1)}{2}} / 2 f_{\mathrm{o}}$

II. $\mathrm{L}=\frac{c}{2 f o \sqrt{\epsilon r}}-2 \Delta L$

III. $\in \mathrm{e}=\frac{\in r h 1+\in r h 2}{h 1+h 2}$

IV. $\Delta L=\frac{0.412 h[(\in \mathrm{r}+0.300)(\mathrm{W} / \mathrm{h}+0.264)]}{(\in \mathrm{r}-0.258)(\mathrm{W} / \mathrm{h}+0.8)}$

Where, $r \mathrm{r} 1$ is the FR4 dielectric constant, $\varepsilon r 2$ is the air gap dielectric constant, $\mathrm{h} 1$ is the FR4 substrate thickness and $\mathrm{h} 2$ is the air gap thickness. Afterwards, the patch width (W) and length (L) have been calculated by considering air gap thickness $h$.

\section{HIGH GAIN MICROSTRIP PATCH} ANTENNA DESIGN

As per the geometry of the proposed antenna, the antenna is realized using double sided copper clad laminate sheet. The lower layer of the FR4 substratre acts as the ground plane which is of $100 \mathrm{~mm} * 100 \mathrm{~mm}$ dimensions, while the radiating rectangular patch of $37 * 46 \mathrm{~mm}$ is designed at 
the upper layer.Feeding point at $10 \mathrm{~mm}$ will be fixed at the Floating copper which acts as the feeding network using microstrip probe feeding technique. The air gap is selected as $3.5 \mathrm{~mm}$

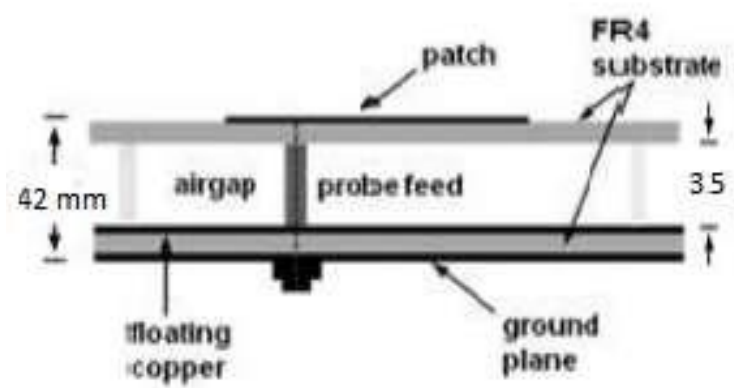

Fig.1: side view of double layer with air gap

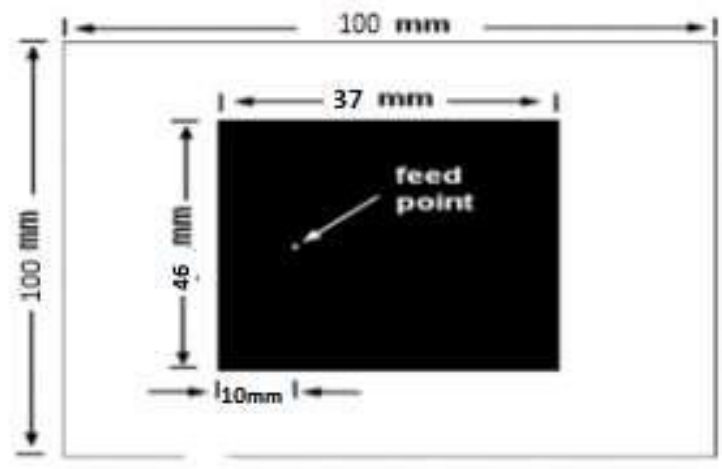

Fig.2: Geometry of top view the high gain Rectangular Microstrip patch Antenna

\section{SIMULATION RESULTS AND COMPARISONS}

\section{A Antenna Gain}

Figure shows the comparison results of gain by introducing different air gap thichness.

TABLE 1

\begin{tabular}{|l|l|}
\hline Air gap $(\mathrm{mm})$ & Gain $(\mathrm{dB})$ \\
\hline $2 \mathrm{~mm}$ & 8.9 \\
\hline $3 \mathrm{~mm}$ & 9 \\
\hline $3.5 \mathrm{~mm}$ & 10.6 \\
\hline $4 \mathrm{~mm}$ & 8.3 \\
\hline $5 \mathrm{~mm}$ & 5 \\
\hline
\end{tabular}

The table shows that the proposed antenna is optimized at $3.5 \mathrm{~mm}$ air gap distance.
Total Field Gain vs. Frequency

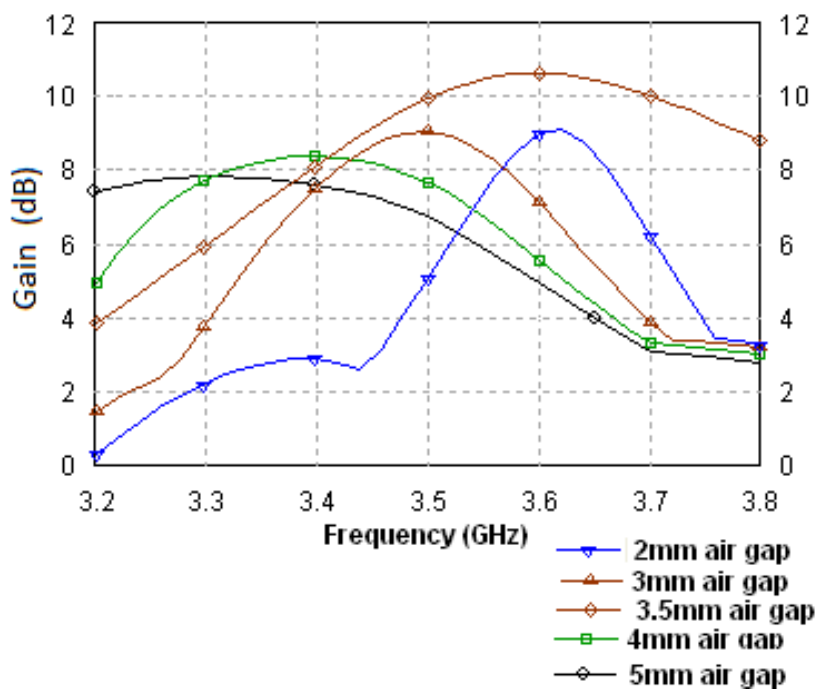

Fig.3: Simulated antenna gain versus the airgap thickness graph

$B \quad$ Voltage Standing Wave Ratio

VSWR is the way to see how much the system is matched .It is the ratio between the maximum voltage and minimum volatage in transmission line.For the best value of antenna ,it should be equal to 1.In this optimized structure structure the VSWR is between 1 and 2

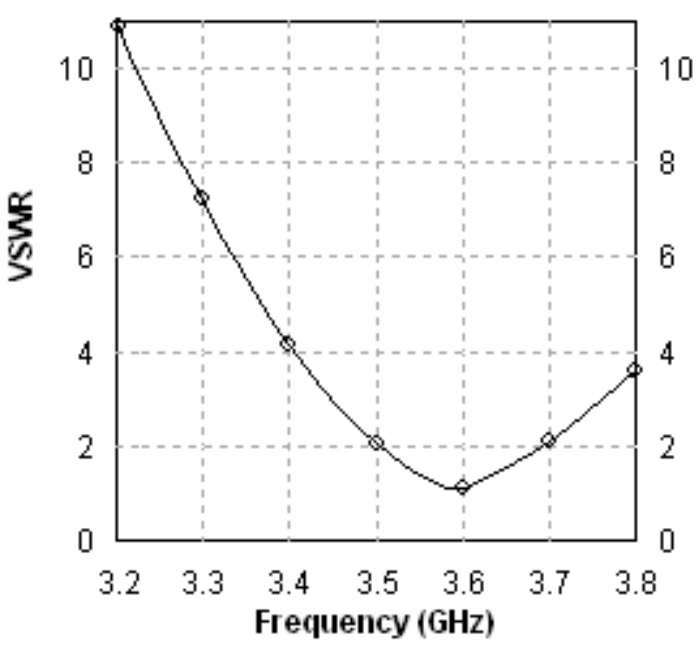

C Return loss

Return loss is the measurement from which we can judge how much amount of power is reflected back by the antenna. Return loss value for the proposed antenna is $-24 \mathrm{~dB}$ 


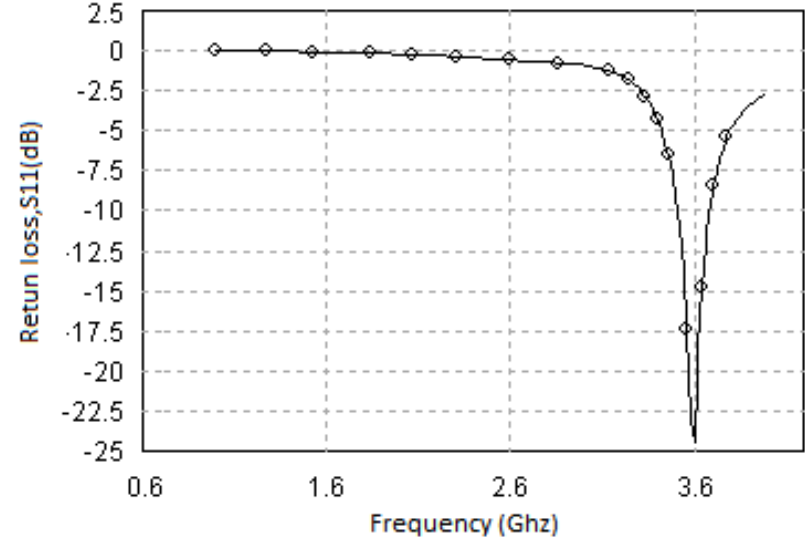

(a)
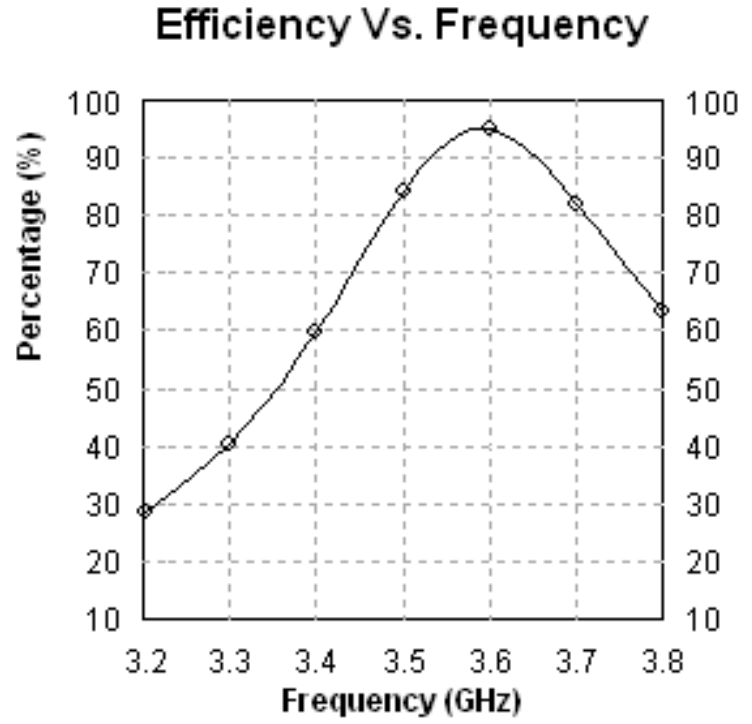

(b)
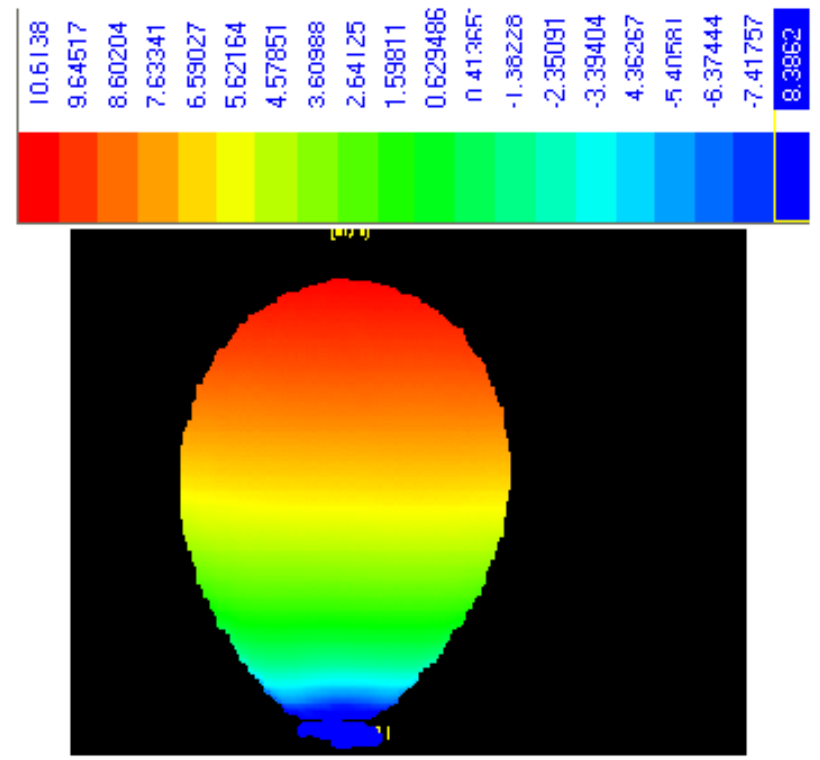

(c)

Fig3 (a) Return loss result at $3.6 \mathrm{Ghz}$ resonating freq.(b)Efficency versus Frequency.(c) $3 D$ Radiation Pattern of standard microstrip rectangular patch antenna

\section{CONCLUSION}

The microstrip patch anenna is widely used antenna design and has a big potential in Wimax communication system. This paper has successfully designed Rectangular patch antenna operating at 3.6 Ghz. Here we have increased the performance of the antenna by improving certain essential parameters such as VSWR, Gain, and Return loss and tried to overcome some if its disadvantages of low gain by introducing a $3.5 \mathrm{~mm}$ air gap.. The optimised structure provides a maximum gain of $10.5 \mathrm{dBi}$, R.L $<-9.5 \mathrm{~dB}$,efficiency of more than $90 \%$ and VSWR between 1 and 2. Gain and efficiency can be further improved by using array antenna.

\section{REFERENCES}

[1] Hassan Sajjad, Waleed Tariq Sethi, Khan Zeb, Adnan Mairaj," Microstrip Patch Antenna Array at 3.8 GHz for WiMax and UAV Applications" IEEE International Workshop on Antenna Technology 2014

[2] Srisuji. T, PG Scholar, Nandagopal. C, Asst. Professor," Analysis on Microstrip Patch Antennas for Wireless Communication" IEEE sponsored $2^{\text {nd }}$ International conference on Electronics And Communications Systems-ICECS 2015

[3] Kadir Ozene and M.Emre Aydemir,Ahmet Oncu "Design of a 1.26 Ghz High Gain Microstrip patch Antenna Using Double Layer with Air Gap for Satellite Reconnaissance " 97S-1-4673-6396-9 IEEE 2013

[4] Surya Sevak Singh, Sheetal R. Bhujade "Design and Evaluation of High Gain Microstrip Patch Antenna Using Double Layer with Air Gap "International Journal on Recent and Innovation Trends in Computing and Communication Volume: 3 March 2015

[5] Sheetal Bhujade, Surya Sevak Singh "Low Profile, High Gain Microstrip Patch Antenna" International Journal of Computer Applications , International Conference on Advances in Science and Technology (ICAST-2014).

[6] Priyanka Kakaria , Rajesh Nema "Review and Survey of Compact and Broadband Microstrip Patch Antenna" IEEE International Conference on Advances in Engineering \& Technology Research (ICAETR - 2014)

[7] Kumari Nidhi Lal, Ashutosh Kumar Singh "Modified Design of Microstrip Patch Antenna for Wimax Communication System " in Proc of the IEEE Students Technology Symposium -2014.

[8] 8 S. C. Gupta, Ajay Singh "Review and Survey of Broadband Microstrip Patch Antennas" International 
Journal of Computer Applications (0975 - 8887)

Volume 59- No.10, December 2012

[9] A.A Qureshi, M.U Afzal,T.Tauqeer,M.A Tarar "Performance analysis of FR-4 substrate for high frequency microstrip antenna " Microwave Conference Proceedings (CJMW) IEEE ,May 2011

[10]Balanis C.A ,"Antenna Theory Analaysis and Design, John Wiley \& Sons 2005

[11] Arun K. Saurabh , Sunil Kumar, D. K. Srivastava "Design and Bandwidth Enhancement of Rectangular Microstrip Patch Antenna using Double H-Slot Technique for Broadband Applications" International Journal of Advanced Research in Computer and Communication Engineering Vol.2, Issue 12, December 2013

[12] Supriya Jaiswal, Haneet Rana, Paurush Bhulania "Microstrip Patch Antenna Array Design And Simulation" International Journal Of Advance Research In Science And Engineering IJARSE, Vol. No.2, Issue No.6, June, 2013

[13] S. Murugan , V.Rajamani "Study of Broadband circularly polarised microstrip antennas", International Conference on Science, Engineering and Management Research ICSEMR

[14] Kharade A.R., Patil V.P "Enhancement of Gain of Rectangular Micro Strip Antenna Using Multilayer Multidielectric Structure" IOSR Journal of Electronics and Communication Engineering, Volume 2, Issue 6 (Sep-Oct 2012)

[15] K.Praveen Kumar1 , K.Sanjeeva Rao" The effect of dielectric permittivity on radiation characteristics of co-axially feed rectangular patch antenna: Design \& Analysis" International Journal of Advanced Research in Computer and Communication Engineering Vol. 2, Issue 2, February 2013 